\title{
Diego Martínez Barrio y el partido de Unión Republicana en Sevilla
}

\section{ANGELES SAMPEDRO TALABAN LEANDRO ALVAREZ REY}

\section{INTRODUCCION: EL REPUBLICANISMO EN SEVILLA A COMIENZOS DEL SIGLO XX}

A comienzos del siglo XX y entre los distintos grupos enfrentados al sistema político diseñado por Cánovas, el republicanismo' seguía representando una de las opciones de mayor peso y relevancia, contando incluso con un arraigo no desdeñable en los estratos medios y bajos de la sociedad española. No obstante, sus perennes rencillas y disensiones internas, a pesar de las momentáneas ilusiones que despertó la aprobación del sufragio universal -en las elecciones de 1891 consiguieron unos treinta diputados-, quedarían bien patentes desde fines de los ochenta en el fracaso de las llamadas uniones republicanas, alianzas coyunturales que a duras penas pudieron sobrevivir a unas diferencias doctrinales y personales, al parecer, poco menos que insuperables. Aún así, los republicanos iniciaron el nuevo siglo convencidos de que era necesario reagrupar a sus diferentes tendencias en una única entidad organizativa. Este propósito cristalizó el 25 de marzo de 1903 con la celebración de una magna asamblea en Madrid, a la que se adhirieron miles de representantes y delegados de provincias. Como es sabido, en dicha reunión quedaron fijadas las bases de la Unión, bajo la jefatura de don Nicolás Salmerón y Alonso (1).

(1) Véase ARTOLA GAlleGO, M.: Partidos y programas políticos, 1808-1936, Madrid, 1974, vol. I, pp. 383-394. Sobre el republicanismo en estos años cfr. especialmente los trabajos de ALVAREZ JUNCO, J.: El Emperador del Paralelo. Lerroux y la demagogia populista, Madrid, 1990, y DARDE MORALES, C.: "Los partidos republicanos en la primera etapa de la Restauración (1875-1890)", en JOVER ZAMORA, J.M.: El siglo XIX en España. Doce estudios, Barcelona, 1974, p.p. 433-464 y "Los 
Unas semanas después, a mediados de abril de 1903, las organizaciones republicanas radicadas en Sevilla formalizaron su fusión en un multitudinario acto celebrado en el Teatro Cervantes de la capital andaluza. En ese momento había censados en la provincia 67 Círculos Republicanos, existiendo algún tipo de organización -junta, sección o comité- en 73 de sus cien municipios. Prácticamente la totalidad de las personalidades representativas del republicanismo hispalense (Alejandro Guichot, José Rubio Gali, Angel María Camacho, Juan Pérez Gironés, José Marcial Dorado, Feliciano Candau, etc.) ingresaron en la llamada Unión o Conjunción Republicana, recayendo la jefatura provincial en la persona de José Montes Sierra (2).

Hombre enérgico, a pesar de su avanzada edad -había nacido en Granada en 1846-, el líder republicano en la Sevilla de comienzos de siglo almacenaba unas considerables dosis de experiencia y madurez, fruto de sus cuarenta años de actuación política activa. Este sedimento y su extracción social burguesa (3) habían configurado una personalidad esencialmente moderada, opuesta a cualquier tipo de extremismo. Incluso, unos años antes de su elevación a la jefatura de Unión Republicana, Montes Sierra había ejercido la presidencia de la Unión Nacional en Sevilla, lo cual significaba -como bien apunta Javier Tusell- la adopción por el máximo director del republicanismo hispalense de una postura momentáneamente posibilista ante el problema de la forma de gobierno (4).

A pesar del acusado moderantismo de su principal dirigente, circunstancia que a duras penas podía satisfacer a los elementos más avanzados, el reagrupamiento en Unión Republicana no tardó en

republicanos", en Historia General de España y América, Madrid, 1982, vol. XVI-2, pp. 130-156. Un buen estudio centrado en una provincia andaluza en ARCAS CUBERO, F.: El republicanismo malagueño durante la Restauración (1875-1923), Córdoba, 1985. Puede consultarse una bibliografía muy completa y actualizada en ALVAREZ JUNCO, J., op. cit., pp. $477-487$ y DUARTE, A.: "El republicanismo decimonónico (1868-1910)", Historia Social, Valencia, n. 1 (1988), pp. 120-126.

(2) La información procede del semanario El Baluarte (Sevilla), correspondiente a los meses de abril-mayo de 1904.

(3) Montes Sierra, católico practicante, era banquero de profesión y consejero del Banco de España. Director de la Compañia Sevillana de Navegación a Vapor, ejerció en varias ocasiones la presidencia del Centro Mercantil, la Cámara de Comercio y la Sociedad Económica de Amigos del País de Sevilla. Cfr. SANCHEZ MANTERO, R.: "Los diputados sevillanos durante la Restauración", Archivo Hispalense, Sevilla, n.․ 220 (1989), pp. 33-49.

(4) Cfr.: TUSELL GOMEZ, J.: Oligarquia y caciquismo en Andalucia, 1890-1923, Barcelona, 1976 , pp. 400 y ss. 
manifestar sus efectos positivos desde el punto de vista de la acción política: durante algunos años y especialmente entre 1906 y 1909, los republicanos. llegaron incluso a contar con una mayoría relativa en la corporación municipal sevillana. Además, en las elecciones generales de 1905 Montes Sierra fue incluido en el encasillado y obtuvo su acta de diputado por la circunscripción de Sevilla, lo cual, en otras :palabras, equivalía a un reconocimiento por parte del sistema de la pujanza del republicanismo local.

Paradójicamente ya desde 1904 y desde las propias filas de Unión Republicana comenzaron a proliferar las críticas contra la pasividad de su minoría municipal, al tiempo que se denunciaban connivencias con los partidos monárquicos y la puesta en práctica por Montes Sierra de métodos supuestamente caciquiles en la dirección del partido. Los enfrentamientos llegaron a tal extremo que en mayo de ese mismo año fueron expulsados de U.R. el editor Juan Pérez Gironés y su periódico $E l$ Baluarte, principales difusores de las ideas republicanas en Sevilla desde hacía veintiocho años. Lo cual acalló momentáneamente las críticas, que sin embargo resurgieron en 1907 con motivo de la nueva inclusión de Montes Sierra en el encasillado. Aunque el jefe de los republicanos negó pública y categóricamente las acusaciones de transigencia y pacto con los monárquicos, la correspondencia de estas fechas entre Antonio Maura y sus amigos políticos en Sevilla desmienten sus declaraciones (5). El aumento de los disconformes con el proceder de Montes Sierra provocaría una primera desbandada en las filas de Unión Republicana, algo que se repetiría en 1910 y prácticamente por idénticos motivos. La asamblea de U.R. celebrada en junio de ese año no ahorró las críticas contra la gestión de su jefe, cuya autoridad fue puesta en entredicho. Casi simultánea en el tiempo, la visita de Alejandro Lerroux a sus simpatizantes en la capital andaluza no hizo sino evidenciar dicha división y los enfrentamientos existentes en el seno del republicanismo local.

Desalentado al fin por las continuas acusaciones de entendimiento y pacto con los sectores monárquicos, ante las elecciones de 1914 Montes Sierra acabó presentando su renuncia a la jefatura del Partido

(5) Al parecer, después de arduas negociaciones se había conseguido consensuar una lista con los nombres de los candidatos y los distritos por los que saldrían elegidos. "La combinación -escribía Hilario del Camino a Maura- se basa en dejar uno de los lugares de las mayorías en la circunscripción para que pueda cómodamente ocuparlo el republicano...". Para ello había sido necesario sacrificar incluso a un preminente conservador, José Bores y Lledó, ex-diputado y futuro presidente del Partido Maurista en Sevilla. Todo el asunto en Archivo Antonio Maura (Madrid), Carta de Hilario del Camino a Maura, 4-4-1907, Legajo 20. 
Republicano de Sevilla. A pesar de ello, aún alcanzaría el acta de diputado en dos ocasiones, por descontado con el visto bueno de los partidos del "turno", antes de su muerte el 2 de mayo de 1918. No obstante, a esas alturas el republicanismo que acaudillase Montes Sierra, plenamente "domesticado" e inserto en un sistema reputado como corrupto, oligárquico y caciquil, no conservaba ya sino una sombra de su antigua y aparente pujanza.

\section{LA TRAYECTORIA POLITICA DE MARTINEZ BARRIO (1905-1931)}

Frente a ese republicanismo elitista y moderado de Montes Sierra resulta constatable en Sevilla ya desde comienzos de siglo la existencia de una corriente progresista y avanzada, cuyo núcleo más representativo era el que giraba en torno a la personalidad de Martínez Barrio.

Nacido en Sevilla el 25 de noviembre de 1883, era, según su propio testimonio, hijo de un albañil y de una vendedora del mercado, que murió cuando él contaba apenas once años. Hombre tenaz y autodidacta, siendo apenas un adolescente y aún antes de ingresar en el servicio militar figuró en grupos anarquistas, llegando a participar como orador en varios mítines societarios (6). Poco después se acercaría a las ideas de la democracia republicana, influyendo notablemente en esta evolución su contacto y amistad con el teniente coronel García Ruíz, hermano de una destacada personalidad de la Primera República y jefe del Batallón de Cazadores de Chiclana, de guarnición en Ronda. Apenas cumplidos los veinte años ingresó en la Juventud Republicana de Sevilla, hasta que dos años después, hacia 1905, un impulso "sentimental y romántico", según propia confesión, acabaría llevándole tras los pasos de Alejandro Lerroux, fascinado por la vibrante personalidad del “Emperador del Paralelom (7).

(6) Véase, por ejemplo, su colaboración en el "semanario obrero independiente" justicia!, de Sevilla: "Notas al aire", 7-12-1902; o "El mitin corchotaponero", en El Pais (Sevilla), 14-7-1904, entre otros muchos

(7) Los datos biográficos sobre Martínez Barrio proceden de sus propias Memorias, Barcelona, 1983; de PRIMELLES, C.; BARBERAN, J.L. y MONTENEGRO, B.: Los bombres que trajeron la República, Madrid, 1932 (1.. ed. 1931), en especial pp. 67-70; ALONSO BAÑO, A. y otros: Homenaje a Diego Martinez Barrio, París, 1978 (pp. 15-40); de la documentación desperdigada por varios Archivos: A.H.N. de Salamanca, secciones "Masonería" y "Político-Social" (series Madrid y Valencia); Archivo Municipal de Sevilla; Archivo Giménez Fernández, etc. De un buen número de periódicos de la época y de Memorias y testimonios de sus coetáneos. Suspapeles personales de 
Acostumbrado al trabajo desde su infancia -a los diez años entró como aprendiz en una panadería-, Martínez Barrio pasó posteriormente por los oficios de impresor, aprendiz de tipógrafo y auxiliar en la Procuradoría de don Rodrigo Rus y Rus, hasta que en 1906 y como empleado de don Manuel Jacinto Martínez entró a trabajar de comisionado en el Matadero Municipal de Sevilla, donde permaneció hasta 1910.(8).

Unos años antes, concretamente en agosto de 1908, los republicanos federales de Sevilla y los miembros de la Juventud Republicana, integrada en su mayoría por adeptos y simpatizantes de Lerroux en la capital andaluza, alcanzaron un principio de acuerdo para agrupar sus respectivas organizaciones en una entidad común, opuesta a la orientación que Montes Sierra estaba imprimiendo a la trayectoria del republicanismo local. La nueva entidad, constituida con el nombre de "Fusión Federalista" (9), adoptaría como cuerpo doctrinal el Manifiesto-

la etapa del exilio fueron donados en depósito, junto con los del Gobiemo de la República, a la Fundación Universitaria Española.

Los escritos de Martínez Barrio que hemos podido localizar hasta la fecha son, aparte de sus propias Memorias, los siguientes: Los radicales en la República. Discursos, Sevilla, Tip: Minerva, 1933; Discurso pronunciado por D. Diego Martinez Barrio en La Coriña, Madrid, s.I., 1934; Páginas para la bistoria del Frente Popular, Madrid, Talleres Gráficos Ed. Ramón Sopena, 1937; Origenes del Frente Popular, Buenos Aires, Patronato Hispano-Argentino de Cultura, 1943; La razón y el sentido de nuestra lucha. Discurso pronunciado en Paris, julio 1938, Madrid, s.l., 1938; España se cree digna y acreedora del triunfo, Discurso pronunciado en la Conferencia Internacional de París, julio 1938, París, s.l. 1938; Un informe, una opinión y una orientación, Valencia, s.l., 1937; Informe político presentado en la Asamblea de Unión Republicana en el exilio, México, s.a. (1944); La Masoneria, fuente de libertad y democracia (en dos Discursos), Cuadernos de Cultura Masónica n. ${ }^{\circ}$ 1, La Habana (Cuba), 1940; Orla de luto y tristeza. La Masonería ha muerto en España... iViva la Masoneria! (Discurso), Cuadernos de Cultura Masónica, n. 2, La Habana (Cuba), 1940; Masones y pacifistas. Comentarios al libro del padre Tusquets. Discurso pronunciado en la Logia "Cbilam Balam", de México, la noche del 18 de abril de 1940, México, s.l., 1940; Prólogo a F. VALERA APARICIO, Tópicos conservadores, Madrid, 1934; Prólogo a J. CABALlERO, Cierzo. El fin de la monarquia española, México, 1944; Prólogo a F. VALERA APARICIO, Alma republicana, Madrid, 1936.

(8) En 1917 contraería matrimonio con Carmén Basset Florindo, viviendo módestamente de los ingresos que les proporcionaba su pequeño negocio, la imprenta "Tipografía Minerva", establecida en la calle Roque Barcia n. 5 (actual calle Lirio). En el piso superior de esta casa, asaltada y desvalijada por los requetés en julio de 1936 y hoy desaparecida, tenia Martínez Barrio su domicilio particular. Durante los años veinte y tras algunas reformas se habilitó una espaciosa sala situada en la planta baja, junto a la imprenta, como "Templo" que compartirian a partir de entonces casi todas las Logias establecidas en Sevilla capital. Martinez Barrio falleció sin dejar descendencia.

(9) Véase "A Todos", La Lucha (Sevilla), 8-1-1909. 
Programa de Pi i Margall de 22 de junio de 1894, auténtico "evangelio de los federales", en opinión de Artola (10). La Fusión consiguió incluso allegar recursos suficientes para publicar, a partir del 8 de enero de 1909 , un modestísimo semanario "republicano-autonomista" titulado La Lucha, heredero de Humanidad y República, periódicos ambos de similar significación y características y editados en Sevilla hacia 19051906. Además, en las elecciones municipales de diciembre de 1909 dos de los candidatos presentados por la Fusión Federalista, Diego Martínez Barrio -que contaba entonces 27 años- y Antonio Sánchez Seco, con el respaldo de los votos de los barrios populares, resultarían elegidos concejales, permaneciendo en la corporación municipal hasta noviembre de 1913.

De estos años data precisamente su primer encuentro con Lerroux, por quien el joven Martínez Barrio -"yo creo haber profesado a Lerroux mayor afecto que el que me tuvo él..."- sentía verdadera admiración. Don Alejandro nos ha dejado en sus Memorias un testimonio muy curioso de este contacto primerizo con el futuro número dos del Partido Radical:

"Continuando la campaña pasamos por Sevilla. Allí permanecía el caciquismo monárquico de Rodríguez de la Borbolla, tan simpático, tan inteligente como persona, y el caciquismo republicano de Montes Sierra, tan áspero y dominante. Frente a ellos se agitaba una juventud llena de positivos valores, en potencia, en capullo o en flor, noble y sinceramente republicana. Entonces conocí a Diego Martínez Barrio, que había dejado hacía poco el servicio militar. De entonces data nuestra amistad..." (11).

Entre esos jóvenes entusiastas e incondicionales se encontraban Manuel Blasco Garzón, Gabriel González Taltabull, José Domínguez Barbero, Julio González Tirado, etc., futuros ministros, gobernadores y diputados a Cortes durante la II República. Casi todos, además, tenían en común su pertenencia a la orden del "Gran Arquitecto del Universo", su adscripción a la Masonería. El propio Martínez Barrio, que alcanzaría en ésta los grados y cargos más elevados, acababa de ingresar el 1 de julio de 1908 en la Logia Fe no 261, de Sevilla, donde fue iniciado con el nombre simbólico de "Justicia", que poco después cam-

(10) Ibidem, pp. 387-388.

(11) LERROUX GARCIA, A.: Mis Memorias, Madrid, 1963, p. 78. 
biaría por el de "Pierre Vergniaud", dirigente de los girondinos durante la Revolución Francesa (12).

Tras su elección como concejal Martínez Barrio, reputado ya como uno de los valores en alza del republicanismo en Sevilla, recibió el apoyo de un anciano correligionario, don Joaquín Maestro Amado, perteneciente a la generación de la Primera República y recién retornado a Sevilla desde la Argentina, donde se había enriquecido. Con su ayuda fundó un nuevo semanario "radical-autonomista", titulado $E l$ Pueblo, cúyo primer número apareció el 25 de mayo de 1910, prolongándose su publicación al menos hasta fines de 1912 (13).

Para esas fechas los republicanos de Martínez Barrio, disuelta su alianza con los federales y adscritos oficialmente al Partido Republicano Radical, contaban ya con un esbozo de organización relativamente importante en la provincia de Sevilla. Para 1911 hay datos que corroboran la existencia de agrupaciones lerrouxistas en al menos 44 localidades, contabilizándose 31 juntas o comités, 24 Centros o Casinos, 8 secciones de Juventudes y 3 Centros Obreros. En justa correspondencia, en las elecciones municipales de noviembre de 1911 los radicales llegaron a presentar hasta 60 candidatos en 14 localidades sevillanas (14). Sin embargo, estos comicios y por causas que resultaría excesivamente prolijo abordar aquí, representarían un duro revés para el Partido Radical y para el conjunto de las organizaciones republicanas de Sevilla, cuya presencia en las instituciones -siquiera testimonial- sufriría un eclipse hasta los últimos años del régimen constitucional.

Del radicalismo en concreto apenas si quedaría otra cosa que la constancia y el tesón de Martínez Barrio, impenitente candidato en todas las elecciones disputadas en Sevilla desde 1917: bien por el distrito de Osuna-Marchena (donde caería derrotado en 1918 frente al marqués de Torrenueva, capitoste conservador, aunque por un estrecho margen de votos); o por la circunscripción de la capital, donde infructuosamente intentaría alcanzar el acta de diputado en junio de

(12) Su expediente masónico se conserva en el A.H.N. de Salamanca, Masoneria, Expediente n. ${ }^{\circ}$ 66/1-A.

(13) El Pueblo, impreso en "Tipografía Gironés" (C/ Francos, 49) se publicó como semanario hasta febrero de 1911; de marzo a abril de 1911 salió tres días en semana, para retornar a su periodicidad inicial a partir de mayo de ese mismo año. En 1922 tuvo una segunda época y recién proclamada la República, en junio-julio de 1931, los radicales lanzaron un diario con la misma cabecera, del que sólo llegaron a publicarse once número.

(14) La información procede de El Pueblo, de Sevilla; y El Radical, de Madrid, en 1910 y 1911 
1919, en una candidatura de la que también formaría parte el propio Alejandro Lerroux; derrotas que volverían a repetirse en diciembre de1920 y en las legislativas de abril de 1923, que precedieron al golpe de estado de Primo de Rivera (15).

Mejores resultados obtendrían los radicales y el propio Martínez Barrio en las municipales de abril de 1920, cuando, convertido ya desde el año anterior en jefe indiscutido de los republicanos de Sevilla, éstos consiguiesen llevar a la corporación municipal a cuatro concejales de su significación: a Martínez Barrio; Hermenegildo Casas Jiménez (secretario general del PSOE durante los años treinta y diputado a Cortes); Gabriel González Taltabull (futuro gobernador civil de Cádiz en 1931, vocal del Tribunal de Garantías Constitucionales y diputado en 1936) y a Manuel Sánchez Suárez (presidente del Partido Radical-Socialista y teniente de alcalde durante el primer bienio republicano).

El golpe de estado de Primo de Rivera y la implantación de la Dictadura a partir de septiembre de 1923 alteraron sustancialmente las condiciones en que se había desenvuelto la trayectoria de los grupos republicanos en Sevilla. Ante las medidas impuestas por el nuevo régimen (restricción del derecho de reunión; prohibición de toda propaganda e información política que no procediese de los canales y organismos oficiales; censura de prensa, etc.), los republicanos apenas si pudieron hacer otra cosa que manifestar su disconformidad con algunos gestos testimoniales, como la negativa de sus concejales a acudir a la sesión extraordinaria en que debía resignar sus poderes la corporación municipal sustituida por Real Decreto (octubre de 1923); o su propósito de que la junta directiva del Ateneo de Sevilla elevase una protesta formal al Directorio por la orden de deportación de Unamuno y Rodrigo Soriano y la clausura del Ateneo de Madrid (febrero de 1924), intento frustrado y que daría lugar a que un buen número de socios republicanos -encabezados por Martínez Barrio y Demófilo del Buen- se dieran de baja en la docta Casa. Sabemos también que en

(15) De hecho en 1923 Martínez Barrio fue elegido diputado por mayoria de votos en Sevilla capital, pero un espectacular "pucherazo" en los pueblos adscritos a la circunscripción entregó el acta al encasillado Juan Ignacio Luca de Tena. Ni la Junta del Censo ni el Tribunal Supremo quisieron reconocer la burda maniobra, pero Luca de Tena, impresionado por el escándalo, se negó a tomar posesión del acta. De este gesto caballeroso data la amistad que desde entonces mutuamente se profesaron. Sobre estas elecciones puede verse: ALVAREZ REY, L.: Sevilla durante la Dictadura de Primo de Rivera: la Unión Patriótica (1923-1930), Sevilla, 1987, pp. 37-64. 
marzo de 1924 el delegado gubernativo de Morón de la Frontera remitió a Presidencia del Gobierno un cuestionario "sospechoso", enviado a los republicanos del distrito y del cual había logrado agenciarse una copia "fruto de mis indagaciones acerca de la población..." (16).

Pero, a pesar de que a los talleres y Logias masónicas -curiosamente semi-toleradas por la Dictadura- comenzaron a llegar un buen número de afiliados procedentes no sólo de las filas republicanas, sino también socialistas, sindicalistas, ex-liberales, etc., haciéndose realidad el próposito de Martínez Barrio de convertir a la Masonería en una especie de cuartel de invierno o "de refugio donde acudan todos los hombres libres, amantes del progreso y de la libertad" (17), los republicanos, salvo raras excepciones, no dieron como tal organización política demasiadas señales de actividad durante los primeros años de la Dictadura. Como señala Octavio Ruíz Manjón, "al igual que otros sectores políticos, los republicanos se limitan a no prestar su colaboración al nuevo régimen, pero no pensaban presentarle ningún obstáculo generalizado" (18).

De todas formas, con el paso del tiempo también los republicanos comenzaron a salir de las catacumbas. En este sentido merecen destacarse las gestiones realizadas por el propio Martínez Barrio para el ingreso de los republicanos sevillanos y onubenses en la Alianza Republicana (19). Y, en la misma línea, el acto semi-clan-

(16) A.H.N., Presidencia del Gobiemo (Dictadura), Legajo 331, caja 1로, $5-3-1924$.

(17) Sobre la trayectoria de la Masonería en estos años puede verse FERRER BENIMELI, J.A.: Masonería española contemporánea, Madrid, 1980, vol. II y GOMEZ MOLLEDA, M.D.: La Masonería en la crisis española del siglo XX, Madrid 1986. Sobre la Mạsonería en Sevilla cfr. ALVAREZ REY, L.: "Masonería y partidos políticos en la Sevilla de la II República (1931-1936)", Actas del III Symposium de Historia de la Masoneria Española, Zaragoza, 1989, vol. I, pp. 205-214 y "La Masonería en Sevilla. Eritre el compromiso y la militancia política (1900-1936)", Actas del IV Symposium de Historia de la Masonería Española, Zaragoza, 1990, vol. II, pp. 227-262.

(18) RUIZ MANJON, O.: El Partido Republicano Radical, 1908-1936, Madrid, 1976, p. 126.

(19) La Alianza Republicana fue fundada a comienzos de 1926 por acuerdo de unos 450 Centros republicanos de toda España. Según Shiomo Ben-Ami, la Alianza "incorporó a su plataforma reivindicaciones sociales y económicas propias de programas "modernos". En cambio otros autores lo consideran un intento de unión "excesivamente utópico y falto de homogeneidad". Cfr. al respecto: BenAmi, Sh.: "Hacia una comprensión de la Dictadura de Primo de Rivera", Revista del Departamento de Derecho Político, Madrid, n. 6 (1980), pp. 107-132; RUIZ MANJON-CABEZA, O'.: El Partido Republicano Radical, 1908-1936, Madrid, 1976, pp. 129-133; AVILES FARRE, J.: La izquierda burguesa en la Segunda República, Madrid, 1985, pp. 35 y ss. etc. 
destino que tuvo lugar en Sevilla el 11 de febrero de 1926, en los locales de la Tertulia Republicana, y que congregó a más de doscientos cincuenta personas con motivo de la conmemoración de la Primera República. Junto a lo más granado del republicanismo local acudieron también algunos dirigentes y ex-diputados del Partido Liberal, enviando representaciones unos veinte pueblos de la provincia. Al parecer, actos similares se celebraron en Ecija, Marchena, Morón y Guillena (20).

Ya en la etapa final de la Dictadura y según algunos indicios fue el propio Martínez Barrio, auxiliado por uno de sus hombres de confianza, Ramón González Sicilia, el encargado de organizar en Sevilla la conspiración que a comienzos de 1929 encabezó Sánchez Guerra. Según refiere Marco Miranda, el líder republicano estaba implicado también en el pronunciamiento que en enero de 1930 preparaba en Cádiz el general Goded (21). De estas fechas data una entrevista que Martínez Barrio concedió a El Noticiero Sevillano y que consiguió eludir el filtro de la censura. En ella mostraba su preocupación por la escisión que a mediados de 1929 habían protagonizado Jiménez de Asúa, Marañón, Pérez de Ayala y Marcelino Domingo de la Alianza Republicana, juzgándola como "un rudo golpe" a la formación de un amplio frente republicano. Del mismo modo, declaró que Sevilla necesitaba "de una fuerza orgánica que, desde el poder o desde la oposición, contribuya a salvar los difíciles momentos que se le avecinan", abogando por la reorganización del republicanismo "sobre una amplísima base, estableciendo como postulado único el de afirmar la convicción de que la República es actualmente la solución política a las necesidades y situación del país" (22). En concordancia con estos posicionamientos, a comienzos de diciembre de 1929 se procedía a la renovación de la Tertulia Republicana y de la Junta Municipal del "Partido Republicano Autónomo" de Sevilla, encargada de reorganizar y coordinar la actuación de todos los núcleos republicanos de la provincia. La presidencia de ambos organismos recayó en Diego Martínez Barrio.

(20) Sobre estos actos véase El Liberal (Sevilla), 10 y 12-2-1926 y La Unión (Sevilla), 13-2-1925.

(21) Cfr.: TUSELL GOMEZ, J.: La crisis del caciquismo andaluz (1923-1931), Barcelona, 1977, p. 223 y MARCO MIRANDA, V.: Las conspiraciones contra la Dictadura, Madrid, 1930, p. 116.

(22) El Noticiero Sevillano, 11-8-1929. 


\section{LA EXPERIENCIA DEL PRIMER BIENIO REPUBLICANO}

En el Archivo de Salamanca y en el voluminoso expediente relativo a Martínez Barrio -fruto de las requisas e incautaciones practicadas por los "nacionales". a partir de julio de 1936- se conservan, junto a cartas de amor de su juventud y abundantes documentos personales, una interesante correspondencia fechada en los meses que precedieron a la proclamación de la República. Martínez Barrio, que contaba entonces 48 años y que arrastraba tras de sî un cuarto de siglo de militancia en los ideales de la democracia republicana, había tenido que exiliarse a Francia tras el fracaso del movimiento revolucionario de Jaca, en diciembre de 1930, ante el temor de una nueva detención como la ya padecida durante la Dictadura (23).

Desde Hendaya y en carta fechada en febrero de 1931 escribiría a su amigo Francisco Saval, de Málaga, asegurándole que el rey estaba "herido de muerte" y que en el plazo de unos meses habría República en España, siempre y cuando sus partidarios se mantuviesen unidos y cohesionados. "Una tarea importante -decía a comienzos de marzocumple actualmente a todas las izquierdas: la de triunfar ruidosa, ampliamente en la elecciones municipales que van a convocarse. No es el próximo un problema electoral, sino una manifestación plebiscitaria sobre la continuación o licenciamiento de la monarquia". En aquellos momentos la gran preocupación de Martínez Barrio parecía constituirla la posible división en el campo republicano por "pasiones minúsculas o rencillas de carácter personal". Por ello era necesario "transigir temporalmente con quienes tienen con nosotros afinidades ideológicas, aunque el punto de contacto sea poco menos que imperceptible. Cuando a mí me flaquea la voluntad, para perseverar en la conducta dirijo atrás la mirada, pienso en 1873 , y tomo alientos nuevos que expulsen toda tentativa de desunión...". Sólo cuando se hubiera logrado el fin primordial y emprendida la tarea de consolidación de la República, sería necesario deslindar actitudes, definir las posiciones en el terreno de las ideas e intentar poner freno "a las insensateces del comunismo" (24).

(23) Que sepamos Martínez Barrio fue detenido al menos en una ocasión en junio de 1925. En enero de 1931 el comandante juez instructor del Regimiento de Soria n.. 9 solicitó con urgencia a la Alcaldía de Sevilla informes sobre el líder republicano. Véase Archivo Municipal de Sevilla, Negociado de Estadística, expediente n. ${ }^{\circ}$ 4 (1931), oficio de fecha 16-1-1931.

(24) Cartas de Diego Martínez Barrio (Hendaya) a Francisco Saval (Málaga), 14-2; 33 y 8-3-1931, en A.H.N. de Salamanca, Masonería, Expediente n.o 66/1-A. 
Dos meses después de la redacción de estas cartas el antiguo aprendiz de tipógrafo y empleado del Matadero Municipal de Sevilla, republicano y masón, regresaría a su casa, con sus amigos de siempre, pero ahora como Ministro de Comunicaciones en el Gobierno Provisional de la II República Española. El recibimiento que le dispensaron sus paisanos fue apoteósico. Incluso los dirigentes de la patronal, y el mismísimo cardenal Ilundain, revestido de su púrpura cardenalicia, acudirían respetuosos a su casa, a saludar en él al nuevo poder constituido. Henchido de satisfacción y sin saber decir que no, el hombre a quien las derechas sevillanas convertirían en su "bestia negra" particular, motejándole de arrogante, cursi, vanidoso, frío, distante y engreído (25), aceptaría incluso ser fotografiado en una pose poco usual y poco "digna": en la intimidad de su despacho, en pijama, rodeado de libros y papeles y ante su vieja y gastada mesa de trabajo de siempre (26).

El radicalismo, íntimamente asociado en la Baja Andalucía a la figura de Martínez Barrio, no existía en Sevilla como tal agrupación política cuando se produjo la proclamación de la República. El hecho distaba de ser excepcional, pues ha sido constatado también en otras provincias. Así, en Huelva, Granada o Sevilla y con la finalidad de aunar esfuerzos comunes, habían ido constituyéndose a lo largo de 1929 y 1930 una serie de partidos republicanos "autónomos", desligados de toda dependencia de las organizaciones nacionales. No obstante, a título individual sus miembros solían aparecer vinculados a una personalidad relevante, siendo mayoría en el caso de Sevilla los afiliados al Partido Republicano Radical de Alejandro Lerroux. Las previsibles discrepancias sobre los principios en que habría de asentarse el nuevo Estado republicano y la proximidad de las elecciones a Cortes Constituyentes, impusieron una clarificación en el seno de esos partidos "autónomos" y un deslinde de campos y posiciones programáticas.

(25) Tampoco se escapó Martínez Barrio de ser tachado públicamente de "homosexual", algo que, según la mentalidad de las derechas de la época, constituía lo más bajo y ruín en que podía caer un ser humano. Como es sabido, según las derechas, una de las "claves explicativas" de los sucesos vividos durante la II República era la supuesta "homosexualidad" de Azaña, origen, por ejemplo, de "su inquina hacia los militares"... Una opinión más imparcial sobre la personalidad de Martínez Barrio puede verse en TUSELl GOMEZ, J.: Historia de España. El siglo XX, Madrid, 1990, p. 326, quien lo define como un hombre "moderado, honrado y pulcro, ajeno a todo rencor, despecho o deseo de venganza, y que llegó a ser, durante la República, la expresión misma del centro político".

(26) La fotografía citada en el reportaje "El señor Martinez Barrio en la intimidad", La Unión, 8-5-1931. 
A comienzos de mayo de 1931 y coincidiendo con la estancia en Sevilla de Martínez Barrio, la Junta Municipal republicana celebró una de sus reuniones más importantes. En ella el recién nombrado ministro dio lectura a un Manifiesto, advirtiendo previamente que quienes no estuvieran conformes con su contenido no podrían seguir perteneciendo a la agrupación que él presidiría. El documento, suscrito por González Sicilia, La Bandera, González Taltabull y el propio Martínez Barrio, contenía en sus nueve puntos una breve y esquemática declaración de principios. El partido "autónomo" de Sevilla, que adoptaría a partir de entonces la denominación de "Izquierda Republicana", se declaraba a favor de la constitución federal del Estado español, de la libertad de conciencia y culto, de la escuela única y del régimen de propiedad individual, aunque condicionado en su aspecto de función social. La conservación del orden y el sometimiento de todos los ciudadanos a la ley constituían las bases finales de un programa que pretendía estar "tan lejos de utopías irrealizables, como de la timidez y del espíritu conservador de los partidos de derecha". Orientado, por tanto, hacia el centro del espectro político, o, como se afirmaba explícitamente, "inclinado a la búsqueda de una posición central" (27). Casi todos los integrantes del pleno del Partido "Autónomo" aceptaron las bases expuestas y en noviembre de 1931 el Partido de "Izquierda Republicana" de Sevilla ingresó ya de forma oficial en el Partido Radical.

Aunque las elecciones celebradas durante 1931 consagraron a los seguidores de Martínez Barrio como la principal fuerza política en Sevilla (28), el apoyo recibido en las urnas y su presencia en los órganos institucionales no se correspondía en realidad con la débil estructura del partido. Piénsese, por ejemplo, que en mayo de 1931 sólo existían comités del P.R.R. en un $15 \%$ de los pueblos de la provincia. De ahí que una de las principales preocupaciones de sus dirigentes

(27) El Liberal, 9-5-1931. Sobre el ideario de los radicales véase especialmente RUIZ MANJON-CABEZA, O.: El partido Republicano Radical. 1908-1936. Madrid, 1976, pp. 649-676 y "La evolución programática del Partido Republicano Radical", Revista de la Universidad Complutense, Madrid, n. 9116,1979 , pp. 423-442.

(28) Consiguieron 7 escaños de diputados a Cortes de 16 posibles y más de la mitad de los puestos de concejales y alcaldías en los Ayuntamientos de la provincia. Véase al respecto: BRAOJOS, A.; PARIAS, M. y ALVAREZ REY, L.: Sevilla en el siglo $X X$, Sevilla, 1990, tomo II, pp. 114-140. 
consistiese en afianzar su presencia en la capital y, especialmente, extenderla a las zonas rurales. Esta tarea, emprendida desde mediados de 1931, resultó extremadamente laboriosa -de hecho se prolongó hasta bien entrado 1932-, pero sus resultados convirtieron al partido de Martínez Barrio en una poderosa máquina electoral: en cada uno de los diez distritos de la capital se constituyeron otras tantas juntas municipales del Partido Radical, formadas por un número variable de miembros (entre 10 y 15 individuos), elegidos en asamblea por los afiliados del distrito. Su mandato se prolongaba durante un año y los integrantes de estas juntas elegían entre sí y por votación a sus representantes en la Junta Municipal Central o comité local de Sevilla. Asimismo, cada distrito contaba con una serie de jefes de sección, encargados de todo lo relativo a los trabajos y preparativos electorales. Las secciones de Juventudes y femenina se adaptaron también a esta organización por distritos. Además, para su correcto funcionamiento se dispuso la instalación de una red de Centros y Círculos extendida por toda la ciudad, una decena de locales que, aparte de lugar de esparcimiento, albergaban las reuniones y asambleas de afiliados, ciclos de conferencias, oficinas y secretaría, etc. Los incesantes comunicados, reseñas de actos, avisos, citaciones, etc., insertos puntualmente en los diarios locales, son un buen exponente de la intensa actividad desarrollada en estos Centros del P.R.R.

La organización en los pueblos transcurrió de forma más lenta, a juzgar por la información del Registro de Asociaciones conservado en el Archivo del Gobierno Civil. No obstante, entre mayo y octubre de 1931 se constituyeron al menos 23 comités locales, en su mayoría en núcleos próximos a la capital y en los distritos de Carmona-Lora, Utrera y Cazalla de la Sierra. La implantación en la mayoría de las poblaciones rurales no se logró hasta marzo de 1932, coincidiendo con la celebración de una asamblea provincial donde quedó aprobado el reglamento del partido y la composición definitiva de sus órganos directivos (29). En esa fecha existían comités radicales en 86 pueblos

(29) El Reglamento fue publicado íntegro en El Noticiero Sevillano, 6, 11, 12 y 13-31932, órgano durante aquellos meses del Partido Radical en Sevilla. Una información completa sobre la asamblea en El Liberal y El Noticiero Sevillano, 13 al 15-31992. El comité ejecutivo provincial lo formaban todos los cargos del partido (diputados y ex-diputados a Cortes, gobernadores, diputados provinciales, etc.); dos representantes por cada una de las organizaciones constituidas en los diez distritos de la capital y veinte representantes de los comités establecidos en los pueblos. Este órgano se subdividía a su vez en varias comisiones, integrada cada una de ellas por cinco miembros de la ejecutiva. 
y, según la Memoria de la Asamblea Nacional celebrada en octubre de 1932, el partido contaba con algún tipo de organización (Centro o junta local) en 100 de los 102 municipios de la provincia de Sevilla (30). Ninguna agrupación política llegó a alcanzar un arraigo similar en esta provincia durante los años de la II República.

Por otra parte, el carácter esencialmente moderado de los radicales sevillanos aparece frecuentemente refrendado por las declaraciones de su principal dirigente. En una conferencia pronunciada en septiembre de 1931, por ejemplo, el ministro de Comunicaciones defendió el criterio de que la futura Constitución tenía que responder forzosamente a un espíritu transaccional, alejado tanto del sentimiento estático de las derechas tradicionales como de los programas extremistas de signo contrario. La separación entre Iglesia y Estado no debía traducirse en vejaciones innecesarias ni en torpe persecución religiosa, del mismo modo que la defensa de la familia debía conjugarse con la implantación del divorcio, "una conquista de la propia moral y de la misma civilización", para aquellos que lo necesitasen. Para Martínez Barrio el derecho de propiedad debía subordinarse a su función social, y el reconocimiento de las personalidades regionales al mantenimiento de la unidad española. Preconizó, por tanto, un Estado fuerte, pero democrático y eficaz, un Estado que fuera capaz de "nacionalizar la República" y de hacerla amada y respetada por la inmensa mayoría de los ciudadanos (31). Sus discrepancias con los socialistas se pusieron de manifiesto en marzo de 1932, cuando en unas declaraciones a Blanco y Negro, ampliamente difundidas, manifestó que era preciso rectificar el rumbo y el perfil del régimen, y que el apartamiento del Partido Socialista del Gobierno constituía una necesidad insoslayable si se quería consolidar la República y evitar su desbordamiento por la izquierda (32). En parecidos términos se pronunció en julio de 1932, con motivo de la inauguración de la Casa del Partido Radical de Sevilla, exponiendo serios reparos a la aprobación de los proyectos de Reforma Agraria y al Estatuto de Cataluña, tal y como habían sido redactados por las comisiones respectivas (33).

(30) Véase Partido Republicano Radical: Asamblea Nacional Extraordinaria. Octubre 1932, Madrid, 1932, p. 177.

(31) Nuestro pensamiento político en la bora actual. Una conferencia del ministro de Comunicaciones, Señor Martinez Barrio, El Liberal, 8-9-1931.

(32) Actualidades, Blanco y Negro (Madrid, 6-3-1932.

(33) MARTINEZ BARRIO', D.: Los radicales en la República. Discursos, Sevilla, 1933, pp. 53-62 
Resulta evidente, pues, que el Partido Radical en Sevilla estaba muy lejos de defender esas posiciones "sectarias" y "revolucionarias" que las derechas "accidentalistas" y los monárquicos confesos no dudaban en atribuirle. El ingreso en sus filas de antiguos dirigentes del Partido Liberal, encabezados por Manuel Blasco Garzón y Antonio Rodríguez de la Borbolla -diputados a Cortes durante la Monarquía-, y la aparición por su izquierda de agrupaciones con propuestas y programas más avanzados, habían contribuido palpablemente a moderar y templar la acción de los radicales. Pero, paradójicamente, esta situación acabaría generando en Sevilla un grave problema político, casi insoluble: el Partido Radical, con una organización envidiable y convertido gracias a las urnas en el eje y la fuerza nuclear de la política local, se vería progresivamente aislado frente a una derecha nostálgica de la Monarquía y unas extremas izquierdas en abierta confrontación con las instituciones republicanas. Y todo ello al tiempo que la colaboración con el Partido Socialista, sus aliados de 1931, se iba haciendo -desde la óptica de los radicales- cada vez más difícil y problemática. Para Martínez Barrio y sus seguidores, las iniciativas y la política emprendida por los socialistas desde el Gobierno, lejos de posibilitar la atracción de los sectores de la izquierda obrera hacia el régimen republicano estaba consiguiendo justamente el efecto contrario, esto es, desplazar y orientar peligrosamente el rumbo de la República, con todo lo que ello suponía de desvirtuación de la propia legalidad. De ahí su insistencia en la necesidad de "centrar" la República y de que su timón pasase a manos de los "auténticos republicanos", de los herederos de aquella tradición liberal y democrática, comprensiva y fraternal del viejo republicanismo. Así pues, correcto o equivocado su análisis político de la realidad, lo cierto es que los radicales fueron quedándose irremisiblemente solos, aislados frente a una derecha en franca recuperación y una izquierda obrera -anarquistas y comunistas principalmente- lanzada en pos de objetivos revolucionarios.

Situación ésta ciertamente comprometida y que el levantamiento militar de Sanjurjo, con su epicentro en Sevilla el 10 de agosto de 1932, no hizo sino agravar.

En efecto, como es sabido suele afirmarse que el fracaso del golpe provocó una oleada de fervor republicano que hizo posible la rápida aprobación en las Cortes de una serie de proyectos, como el Estatuto de Cataluña o la Ley de Reforma Agraria, que hasta entonces habían tropezado con una seria oposición parlamentaria. Las relaciones entre el Gobierno y los grupos de oposición republicanos, gravemente deterioradas durante los meses que precedieron al estallido del complot, 
parecieron mejorar de forma notable ante la necesidad de ofrecer un frente común y una imagen de cordialidad entre los partidarios de las instituciones democráticas, seriamente amenazadas por los extremismos de uno y otro signo. Incluso en los meses finales de 1932 no faltaron las iniciativas tendentes a amortiguar la fragmentación entre los distintos partidos republicanos, bien a través de la fusión de aquellas organizaciones cuyos programas y afinidades ideológicas resultaban evidentes, o al menos mediante el logro de una actuación coordinada en las labores legislativas.

Pero en Sevilla en cambio y desde mediados de 1932 a lo que se asistió fue a un proceso de continua y acusada atomización entre las fuerzas políticas republicanas. En el Partido Radical los enfrentamientos entre los antiguos afiliados y los recién llegados al partido no tardaron en adquirir carta de naturaleza. Desde abril de 1931 el grupo aglutinado en torno a Martínez Barrio había abierto sus puertas a un buen número de antiguos políticos monárquicos, en su mayoría procedentes de la extinta Izquierda Liberal dinástica (34). La incorporación de estos elementos era vista con recelo y prevención por quienes, como Domínguez Barbero, González Taltabull o González Sicilia, podían acreditar su pertenencia al partido desde hacía diez, quince o veinte años. El dilema en que se hallaban inmersos los radicales poseía en realidad múltiples aristas: de un lado, se habían impuesto el propósito de atraer hacia la República a una serie de elementos políticamente valiosos y con cierto predicamento entre las clases conservadoras; de otro, se veían obligados a mantener una postura de moderación y equilibrio al frente de las instituciones locales, todo lo cual se avenía mal con el pregonado y tradicional "izquierdismo" del partido en Sevilla. Que ese izquierdismo no fuera tal, dada la fijación de los radicales en el espectro político del momento, no resta valor a la afirmación anterior: en palabras de Martínez Barrio, a fin de cuentas "todos somos izquierda con relación a unas cosas y derecha con relación a otras" (35). La defensa de los postulados laicistas y de los principios liberales y democráticos, encarnados en su ideal republicano, bastaban a Martínez Barrio y a la vieja guardia del Partido Radical en

(34) De los problemas de integración entre los viejos dirigentes y los nuevos afiliados al P.R.R. ha dado cuenta pormenorizada RUIZ MANJON, O.: El Partido Republicano Radical, 1808-1936, Madrid, 1976, pp. 347 y 591-592.

(35) MARTINEZ BARRIO, D.: Los radicales en la República. Discursos, (Discurso pronunciado en la Casa del Partido Radical de Sevilla el día 28 de noviembre de 1932), p. 120. 
Sevilla para considerarse como "hombres de izquierda", frente a una derecha caracterizada, desde su punto de vista, por el reaccionarismo de monárquicos y clericales.

El levantamiento de Sanjurjo puso al descubierto muchas suspicacias y resquemores en el seno del partido. Se decía que algunos afiliados habían adoptado el 10 de agosto actitudes equívocas y contraproducentes: visitas a Sanjurjo en Capitanía, ofrecimientos de índole desconocida... También se aludía a la existencia de un "amplio malestar" en ciertos sectores del partido, por las represalias y las destituciones de funcionarios en el Ayuntamiento que siguieron al fracaso de la "Sanjurjada". El 26 de agosto Antonio Rodríguez de la Borbolla, ex-diputado a Cortes durante la Monarquía, anunció su dimisión como miembro de la ejecutiva y su baja en el Partido Radical. El comité replicó con una nota aduciendo que no era Borbolla quien se iba, sino que el 15 de agosto el propio comité ejecutivo había decidido su expulsión del partido (36). De hecho, los rumores sobre una escisión en el Partido Radical venían circulando desde hacía tiempo y ante la evidente confusión que reinaba en sus filas, Martínez Barrio en persona optó por convocar un pleno extraordinario de la junta provincial.

Esta reunión se celebró en los primeros días de septiembre de 1932. Martínez Barrio, que abrió el turno de intervenciones, centró la suya en el análisis de la composición del Partido Radical, señalando la existencia de tres capas de afiliados: los que habían permanecido con Lerroux durante toda su vida; los que llegaron con la etapa Berenguer y aquellos que se habían agregado en los últimos meses. Tres capas que, en su opinión, "no han logrado fundirse en el crisol de la disciplina", dando lugar a corrillos y malquerencias. Propuso entonces que cesaran las pugnas internas y los enfrentamientos personales, en aras de la eficacia de la organización. Enfrentamientos que, sin embargo, se pusieron de manifiesto cuando Bravo Ferrer pidió la palabra y defendió la entrada en el partido de elementos de derechas, gentes de la pequeña y mediana burguesía y "hombres de buena fe" que, según él, no se acercaban a los radicales por el extremismo de que hacían gala algunos de sus directivos. Aunque no citó nombre alguno, la alusión fue recogida de inmediato por Ramón González Sicilia, quien adujo que "si el Partido Radical no es un partido de izquierda, yo me voy", palabras que fueron refrendadas con 
una gran ovación. Martinez Barrio tuvo que terciar en el incidente, pidiendo la unión entre quienes comulgaban en lo esencial con los principios democráticos (37).

El pleno de la junta provincial del P.R.R. adoptó cuatro conclusiones: tres de ellas carecen de verdadero interés, pues se limitaban a ratificar su adhesión a Lerroux y a Martínez Barrio, pidiendo a todos los afiliados unión y disciplina. La cuarta sin embargo disponía que en lo sucesivo todos los cargos públicos quedaban obligados a seguir fiel y escrupulosamente las directrices políticas trazadas por el comité ejecutivo, $_{\text {, sin }}$ perjuicio de que pudieran discrepar de ellas en el pleno de la junta provincial. La reunión finalizó con el nombramiento de representantes para la Asamblea Nacional Extraordinaria del P.R.R., que habría de celebrarse en Madrid a mediados de octubre, recayendo la designación casi exclusivamente en miembros de la vieja guardia radical de Sevilla.

Al día siguiente de celebrarse esta reunión Miguel García y'Bravo Ferrer anunció su separación del partido, poniendo su acta de diputado en Cortes a disposición de la asamblea provincial. Su salida arrastró la de varios concejales del Ayuntamiento de la capital y de otros cargos menos relevantes. Los radicales, cada vez más atrapados en las limitaçiones de su propia indefinición ideológica, intentaron clarificar su posicionamiento en la política local en una tensa asamblea extraordinaria celebrada a finales de noviembre de 1932. Sin embargo; salvo la ratificación del carácter "izquierdista" de la organización, el único acuerdo adoptado fue aplazar el debate y la posible reestructuración del partido a una asamblea provincial suplementaria, que habría de celebrarse a comienzos de 1933. Una asamblea que, en vísperas de la campaña electoral de noviembre, aún no había sido convocada.

\section{LA RUPTURA CON LERROUX Y LOS ORIGENES DEL PARTIDO DE UNION REPUBLICANA}

Tras la caída del Gobierno Azaña en septiembre de 1933 y aceptada por el Presidente de la República la propuesta de Lerroux de formar una mayoría parlamentaria de centro-izquierda exclusivamente republicana, Martínez Barrio añadió un nuevo peldaño a su carrera política al ser designado Ministro de la Gobernación en un efímero gabinete que apenas duró 26 días. Sin embargo, inmediatamente después, el 9 de

(37) El Liberal, 12-9-1932. 
octubre, el líder de los republicanos de Sevilla era nombrado por Alcalá Zamora nuevo Presidente del Consejo de Ministros, pero con la finalidad expresa de disolver las Cortes y convocar elecciones generales para el 19 de noviembre de 1933, con segunda vuelta el 3 de diciembre.

El resultado de las urnas y los efectos del sistema electoral, que perjudicaron notablemente a unas izquierdas que se presentaron desunidas frente al bloque formado por las derechas, dieron paso a unas Cortes muy diferentes en su composición a las del primer bienio republicano. No obstante, el triunfo de las derechas distaba mucho de ser total: los grupos conservadores, aún coaligados, no poseían mayoría absoluta en la Cámara. Por su parte tampoco los radicales, aún con el apoyo del resto de los partidos centristas, poseían el número de diputados suficiente para formar un gobierno con mayoría parlamentaria. La colaboración entre las dos minorías mas nutridas, el Partido Radical de Lerroux y la C.E.D.A. de Gil Robles, que sumaban aproximadamente 220 de los 470 escaños de las Cortes, pareció entonces la única salida posible a esta compleja situación. Así pues, se formó un gabinete de centro, sostenido básicamente por el Partido Radical, que pondría en marcha una política "revisionista" con el apoyo parlamentario de los 115 diputados de la Minoría Popular Agraria.

Martínez Barrio, que aceptó formar parte de los primeros gabinetes del bienio radical-cedista (primero como Ministro del Ejército, pasando después a Gobernación), comenzó a disentir claramente en la primavera de 1934 de la hipoteca que representaba el apoyo de Gil Robles, sintiéndose cada vez más incompatible éticamente para gobernar con quienes consideraba el gran enemigo de la República. La anunciada escisión se consumó en el mes de mayo, con un escrito de despedida que envió a Alejandro Lerroux y que representaba de facto la ruptura del histórico Partido Radical.

Las interpretaciones que distintos autores han ofrecido sobre el porqué de esta escisión son ciertamente contradictorias. Por nuestra parte, las fuentes consultadas parecen indicarnos que fue la presión ejercida por Gil Robles y la C.E.D.A. -de la cual existen testimonios muy reveladores en el Archivo de Salamanca-, proclives a orientar en un sentido inequívocamente conservador la acción de los gobiernos radicales, lo que motivó la escisión del ala más progresista del radicalismo (38). Este sector, con Martínez Barrio a la cabeza, interpretó tal

(38) Hemos abordado esta cuestión con detalle en Sampedro Talaban, M.A.: Uniōn Republicana. Origen, ideologia, estructura y base bumana, T.L.I., Universidad de Salamanca, 1984. 
giro como la puesta en práctica de una política opuesta a los más elementales principios defendidos hasta entonces por el Partido Radical; una política, en suma, a la que éste en modo alguno debía cooperar. Otras causas señaladas tradicionalmente a la hora de enjuiciar tal ruptura, como la supuesta influencia de la Masonería, la actuación de Alcalá Zamora o la inmoralidad de los radicales en la gestión gubernamental; no parecen haber jugado un papel decisivo ni trascendental en el planteamiento y resolución de la crisis (39).

La disidencia del hasta entonces hombre de confianza de Lerroux, que arrastró tras de sí a una veintena de diputados - la mitad de ellos andaluces- tuvo una fuerte incidencia en Sevilla, donde Martínez Barrio gozaba de un gran prestigio personal y donde, en cierta medida, se le identificaba con el republicanismo avanzado y progresista, papel que encarnaría Azaña a nivel nacional. En efecto, tras la ruptura con Lerroux la identificación de los radicales sevillanos con Martínez Barrio fue prácticamente total.

Entre mayo y julio de 1934 Alejandro Lerroux recibió algó más de medio centenar de cartas procedentes de la provincia de Sevilla. En su inmensa mayoría se trataba de particulares que, a título individual, le reiteraban su adhesión y su disconformidad con la decisión de Martínez Barrio. Tan sólo un $15 \%$ de los comités radicales de la provincia decidieron mantenerse fieles a Lerroux, aún a costa de verse desautorizados por sus propias bases. En otras poblaciones, como Ecija, Osuna o El Rubio, grupos de lerrouxistas, por lo general poco nume-

(39) Lo cual no quiere decir que no influyesen para nada. Por ejemplo, resulta obvio que en los talleres masónicos existió malestar y que hubo protestas por lo que había ocurrido en las elecciones de noviembre y por la acción "revisionista" de los primeros gobiernos del bienio radical-cedista. Pero lo que sigue estando 'por demostrar es el presunto papel que la Masonería desempeñó en la escisión, con independencia de que existan autores que se empeñen en hacer ver lo contrario de lo que dice la información que ellos mismos manejan y aportan. Con respecto a Alcalá Zamora, él mismo se encargó de negar su implicación en aquellos acontecimientos. Otra cosa es que el Presidente de la República no lamentase en demasía la escisión, ya que en definitiva ello aumentaba sus posibilidades de maniobrar con los partidos de centro, a la vez que debilitaba una fórmula -la radical-cedista- que nunca fue de su agrado. Finalmente, la inmoralidad administrativa no creemos que actuase como detonante de nada, sobre todo teniendo en - cuenta que la ruptura Lerroux-Martínez Barrio tuvo lugar antes de que dichas acusaciones alcanzasen una especial trascendencia política. 
rosos, se ofrecieron a don Alejandro para constituir comités en su nombre o para ingresar en unos Ayuntamientos cuya "renovación" -es decir, limpieza de socialistas y de adeptos a Martínez Barrio- consideraban inevitable (40).

Frente a esto, todos los diputados, ex-gobernadores y altos cargos de la Administración, los miembros de la ejecutiva y la inmensa mayoría de los alcaldes y cuadros de la provincia, optaron por permanecer al lado del disidente. Como señalaría El Liberal, la organización radical sevillana había obedecido siempre a las orientaciones de su jefe provincial, más que a las conveniencias del partido nacional. Por ello era fácil prever que sólo los incorporados al radicalismo desde el advenimiento del nuevo régimen, elementos procedentes de otras organizaciones, era posible que siguieran a Lerroux (41).

Esta impresión se vería confirmada el 27 de mayo de 1934, cuando el comité ejecutivo y la asamblea provincial del P.R.R. acordasen formalmente su ingreso en la nueva organización presidida por Martínez Barrio, el Partido Republicano Radical-Demócrata (42). En agosto una nueva asamblea de afiliados, convocada por la Junta Municipal de Sevilla, ratificaría el carácter "francamente izquierdista, democrático, laico, autonomista y partidario de todas las reformas de carácter social" del partido liderado por Martínez Barrio (43).

\section{LA ORGANIZACION E IDEOLOGIA DE UNION REPUBUICANA}

La reorganización de los radicales-demócratas en Sevilla comenzó con el nombramiento de una nueva ejecutiva, elegida en asamblea el 10 de septiembre de 1934. Días más tarde, el 20 del mismo mes y conforme a lo acordado por los respectivos comités nacionales, se estableció en la capital andaluza el comité provincial del Partido de Unión Repu-

(40) La correspondencia citada se conserva en el A.H.N. de Salamanca, Politico-Social, serie Madrid, Legajos 39, 40,41, 43, 44 y 97. Para "reorganizar" el lerrouxismo en Sevilla hubo que recurrir a un personaje, Guillermo Moreno Calvo, que elevado a la Subsecretaría de Presidencia acabaría siendo el principal implicado en el "escándalo Nombela". Moreno Calvo se limitó a recurrir a viejos políticos de la monarquía, en su mayoría pertenecientes al extinto Partido Liberal, y que desde 1931 había permanecido alejados de toda actividad política. El resultado fue un desarrollo del nepotismo y la corrupción quizá sin precedentes en la política provincial.

(41) El Liberal, 18-5-1934.

(42) El Liberal, 28-5-1934.

(43) Renacer (Sevilla), 5-8-1934. 
blicana, organismo que contaría con la presencia de los representantes del Partido Radical-Demócrata de Martínez Barrio y del grupo radicalsocialista dirigido por Gordón Ordás (44). Además, la nueva agrupación incrementaría sus efectivos con el ingreso de algunos ex-dirigentes socialistas moderados, como los diputados a Cortes Hermenegildo Casas Jiménez y Adolfo Moreno Quesada; los concejales Romero Llorente y Jiménez Tirado, etc., expulsados reientemente del PSOE.

Con independencia de su organización en la capital, que continuó siendo básicamente la misma que la del primer bienio, el partido de Unión Republicana llegó a alcanzar una notable implantación en el conjunto de la provincia, a pesar de la abierta persecución que lerrouxistas y cedistas desencadenaron contra los seguidores de Martínez Barrio, clausurando sus Centros de forma arbitraria aprovechando el impacto de los sucesos de octubre de 1934. Aún así, durante 1935 y los primeros meses de 1936 la formación de comités fue constante, tal y como refleja el Registro de Asociaciones del Gobierno Civil, alcanzando en este último año la cifra de 45 agrupaciones locales.

Desde su constitución, la influencia ejercida por Unión Republicana de Sevilla en la línea y los principios ideológicos asumidos por el nuevo partido fue notable y su actividad constante. Ya en diciembre de 1934 tuvo lugar el nombramiento de las comisiones encargadas de redactar las ponencias para la asamblea provincial de 1935. Dichas comisiones fueron las siguientes: Política General; Reorganización y Propaganda; Electoral; Enseñanza; Paro Forzoso; Subsistencias; Presupuestos: Municipales; Asuntos Económicos y Sociales y Abastecimiento de Aguas (45). Los asuntos tratados en la asamblea de Sevilla, celebrada a comienzos de 1935, sirvieron de base para la elaboración del Programa de Unión Republicana, tal y como veremos a continuación.

El primer Congreso Nacional de Unión Republicana se celebró en Madrid durante los días 27 al 30 de septiembre de 1935. Al Congreso

(44) La fusión en ABC, 21-9-1934. Sobre este partido véase RAMIREZ JIMENEZ, M.: "La formación de Unión Republicana y su papel en las elecciones de 1936", en Las reformas de la II República, Madrid, 1977, pp. 125-169, y especialmente SAMPEDRO TALABAN, M.A.: Unión Republicana. Origen, ideologia estructura y base bumana, T.L.I., Universidad de Salamanca, 1984.

(45) Los informes y ponencias debatidas en dicha asamblea fueron incautadas por miembros del Requeté durante los primeros días de la Guerra Civil, y actualmente se conservan entre los fondos del Archivo Carlista de Sevilla, sección "Melchor Ferrer", Legajo 19, carpeta año 1935. (fondos no carlistas). Véase también su crónica periodistica en El Liberal, 8-7 y 5-8-1935. 
asistieron unos 800 delegados, que decían representar aproximadamente a 200.000 afiliados.

El documento programático que primero pasó a discusión fue la Ponencia elaborada por la agrupación local de Sevilla (46). Varios eran los puntos señalados en dicho dictamen: Presupuestos, Legislación Social y Obrera, Reforma Tributaria, Monopolios, Política Agraria, Obras Públicas, Subsistencias y Paro Forzoso. Del análisis pormenorizado dé dicha ponencia y de las conclusiones adoptadas por el Congreso Nacional se deduce que los puntos programáticos asumidos por Unión Republicana fueron los siguientes:

1. En primer lugar, defensa inquebrantable de la Constitución de 1931, soporte del Estado republicano.

2. En el orden político, U.R. definía al Estado como una "integración de economías municipales y regionales", dentro de la unidad "indestructible" de España. El partido se mostraba partidario de fomentar, de acuerdo con la Constitución, la personalidad de las regiones españolas que quisieran constituirse en régimen de autonomía.

3. Respecto a la Administración de Justicia, Unión Republicana decía aspirar a su profunda democratización. El pueblo tendría un papel relevante en su reforma con la introducción del sistema de jurados.

4. En política religiosa se mostraba partidaria de la aplicación de los artículos 3, 25, 26, 27 y 28 de la Constitución, y de la rápida ejecución de las leyes aprobadas por las Cortes Constituyentes para su desarrollo.

5. Con respecto a la reforma de la Administración Pública, ésta habría de desarrollarse tomando como norma el principio de eficacia.

6. En Comunicaciones, Unión Republicana solicitaba la gradual aplicación de la Ley de Bases de los Cuerpos de Telégrafos y Correos, y una red telefónica ampliada a los medios rurales.

7. Las reformas sociales que propugnaba el partido intentaban ante todo impulsar el pleno reconocimiento de los derechos individuales de libertad de asociación y de sindicación. En el programa se recogía asimismo la intervención estatal para garantizar unos salarios mínimos en la agricultura y la industria.

8. El programa económico aspiraba a la nacionalización de las aguas, minas, bosques, ferrocarriles y de la tierra, garantizando al agricultor el dominio útil de su propiedad siempre que cumpliera los fines

(46) El documento original, bastante extenso, se conserva en el A.H.N. de Salamanca, Politico-Social, Madrid, Legajo 2.613. 
sociales impuestos por la Constitución. Unión Republicana juzgaba necesaria la creación del patrimonio familiar inembargable, y de una ley de arrendamientos rústicos encaminada a conceder las máximas garantías y beneficios a los cultivadores de la tierra.

9. Respecto a la instrucción pública, el programa recogía el desarrollo de los principios contenidos en la Constitución y la organización de una intensa campaña nacional para lograr la total erradicación del analfabetismo.

10. En materia sanitaria, se pedía la creación del Ministerio de Sanidad y la extensión a toda la población de la asistencia médico-farmacéutica gratuita.

11. Finalmente, las medidas que Unión Republicana propugnaba para acabar con el problema del paro se reducían a la intensificación de las obras públicas. En este aspecto resulta particularmente interesante la ponencia sobre Paro Forzoso elaborada por la agrupación sevillana, en la cual se solicitaba el fomento de la construcción con el apoyo de las instituciones locales (construcción de casas baratas y escuelas públicas), provinciales y nacionales (en relación con el ramo de Guerra). En concreto, para el futuro de la capital andaluza se recomendaba "proyectar obras de utilidad públicas que mejorando los servicios aumenten el capital municipal [...], un proyecto de ensanche de tal importancia que ni siquiera aproximadamente nos atrevemos a calcular lo que pudiera influir en el porvenir de Sevilla..." (47).

En conclusión, un programa plenamente inserto en los objetivos del republicanismo burgués de centro-izquierda y que, como tantas otras cosas, vería truncada bruscamente su trayectoria con el estallido de la guerra civil.

Apenas unas semanas antes Martínez Barrio, elevado a la presidencia del Congreso de los Diputados, le transmitiría al también sevillano Manuel Giménez Fernández, su adversario político y amigo personal, algunas de las preocupaciones que atenazaban su ánimo. En carta fechada el 9 de junio de 1936 y tras referirse a recientes acontecimientos de la política local, le decía lo que sigue:

"Supongo que estará usted informado, independientemente de la versión periodística, del orígen y tramitación de la fugaz retirada parlamentaria de Acción Popular.

(47) Cfr.: Ponencia sobre Paro Forzoso discutida en la Asamblea Provincial de U.R. de Sevilla, marzo de 1935, en Archivo Carlista de Sevilla, sección "Melchor Ferrer", Legajo 19, carpeta año 1935 (fondos no carlistas). 
El señor Gil Robles está cada día de humor más agrio y difícil. Ignora, o se le olvida, que la realidad aconseja una política diametralmente opuesta a la que sigue. De presente, una política impopular entre las masas de derecha. Lo concedo. Pero, ¿quién no se ha visto obligado por el deber, y en procura de mejor porvenir, a remar contra corriente?.

Me ratifico en el juicio, un poco pesimista, que tengo de este momento de la Historia. Aquí todo el mundo propende a la exageración, como si entre las posiciones diversas, y aun antagónicas, no hubiera predicados comunes, los bastantes para facilitar al país una larga temporada de reposo.

Destino, fatalidad, jvaya usted a ver!.

¡Buena vacación se ha tomado!. Quisiera imitarla. Procuraremos que Julio sea benigno y favorable al propósito.

Suyo buen amigo

Diego Martínez Barrio" (48).

En contra de los deseos de don Diego, el mes de julio de 1936 no sería benigno ni favorable al propósito, sino que, bien al contrario, contemplaría el inicio de una de las guerras civiles más crueles y terribles de las que guarda memoria la historia del siglo XX.

(48) Carta de Diego Martinez Barrio (Madrid) a Manuel Giménez Fernández (Chipiona-Cádiz), 9-6-1936, en Archivo Giménez Fernández (sin inventariar). 